\title{
NT-proBNP during and after primary PCI for improved scheduling of early hospital discharge
}

\author{
D. A. A. M. Schellings ${ }^{1,6} \cdot$ A. W. J. van 't Hof ${ }^{1}$ J. M. ten Berg' ${ }^{2}$ A. Elvan ${ }^{1}$ - E. Giannitsis ${ }^{3}$ C. Hamm ${ }^{4}$ \\ H. Suryapranata ${ }^{1,5} \cdot$ A. Adiyaman ${ }^{1}$
}

Published online: 9 December 2016

(C) The Author(s) 2016. This article is available at SpringerLink with Open Access.

\begin{abstract}
Background The Zwolle Risk Score (ZRS) identifies primary percutaneous coronary intervention (PPCI) patients at low mortality risk, eligible for early discharge. Recently, this score was improved by adding baseline NT-proBNP. However, the optimal timepoint for NT-proBNP measurement is unknown.

Methods PPCI patients in the On-Time 2 study were candidates. The ZRS and NT-proBNP levels on admission, at $18-24 \mathrm{~h}$, at $72-96 \mathrm{~h}$, and the change in NT-proBNP from baseline to $18-24 \mathrm{~h}$ (delta NT-proBNP) were determined. We investigated whether addition of the different NT-proBNP measurements to the ZRS improves the prediction of 30-day mortality. Based on cut-off values reflecting zero mortality at $30 \mathrm{~d}$, patients who potentially could be discharged early were identified and occurrence of major
\end{abstract}

Electronic supplementary material The online version of this article (doi: 10.1007/s12471-016-0935-2) contains supplementary material, which is available to authorized users.

$\triangle$ A. Adiyaman v.r.c.derks@isala.nl

1 Department of Cardiology, Isala Klinieken, Zwolle, The Netherlands

2 Department of Cardiology, St. Antonius Hospital, Nieuwegein, The Netherlands

3 Department of Cardiology, Universitäts Klinik, Heidelberg, Germany

4 Kerckhoff Klinik, Bad Nauheim, Germany

5 Department of Cardiology, Radboud University, Nijmegen, The Netherlands

6 Department of Cardiology, Slingeland Hospital, Doetinchem, The Netherlands adverse cardiac events (MACE) and major bleeding until $10 \mathrm{~d}$ was registered.

Results 845 patients were included. On multivariate analyses, NT-proBNP at baseline (HR 2.09, 95\% CI 1.59-2.74, $p<0.001$ ), at $18-24 \mathrm{~h}$ (HR $6.83,95 \%$ CI $2.94-15.84$ ), and at $72-96 \mathrm{~h}$ (HR 3.32, 95\% CI 1.22-9.06) independently predicted death at $30 \mathrm{~d}$. Addition of NT-proBNP to the ZRS improved prediction of mortality, particularly at $18-24 \mathrm{~h}$ (net reclassification index 29\%, $p<0.0001$, integrated discrimination improvement $17 \%, p<0.0001)$. Based on ZRS $(<2)$ or NT-proBNP at $18-24 \mathrm{~h}(<2500 \mathrm{pg} / \mathrm{ml}) 75 \%$ of patients could be targeted for early discharge at $48 \mathrm{~h}$, with expected re-admission rates of $1.2 \%$ due to MACE and/or major bleeding.

Conclusions NT-proBNP at different timepoints improves prognostication of the ZRS. Particularly at $18-24 \mathrm{~h}$ post PPCI, the largest group of patients that potentially could be discharged early was identified.

Keywords STEMI - Serial NT-proBNP - PPCI - Zwolle Risk Score $\cdot$ Early discharge $\cdot$ Major adverse cardiac events (MACE)

\section{Introduction}

Primary percutaneous coronary intervention (PPCI) substantially improved outcome in patients with ST-elevation myocardial infarction (STEMI), which has been paralleled by a decrease in hospital length of stay [1-3]. In addition several studies have demonstrated that most low-risk PPCI patients are eligible candidates for early discharge [4-11].

The Zwolle Risk Score (ZRS) is a simple tool designed to identify PPCI patients who can be safely discharged within $72 \mathrm{~h}$, based on their 30-day mortality risk [11]. In patients 
Fig. 1 Zwolle Risk Score (a) and relative risk (RR) of 30-day mortality for each score (b) (CI confidence interval, STEMI ST-elevation myocardial infarction, TIMI Thrombolysis in Myocardial Infarction) a

Zwolle Risk Score for STEMI

\begin{tabular}{ll|}
\hline Killip class & Points \\
1 & 0 \\
2 & 4 \\
$3-4$ & 9 \\
\hline TIMI flow post & \\
3 & 0 \\
2 & 1 \\
$0-1$ & 2 \\
\hline Age & \\
$<60$ & 0 \\
$\geq 60$ & 2 \\
3 -vessel disease & \\
No & 0 \\
Yes & 1 \\
Anterior infarction & \\
No & 0 \\
Yes & 1 \\
\hline Ischemia time (> 4 hours) & \\
No & 0 \\
Yes & 1 \\
TOTAL SCORE & 16
\end{tabular}

b

$\begin{array}{lccc}\text { Risk Score } & \text { RR [95\% Cl] of death by 30-D } \\ 0-1 & 0.03 & {[0.008-0.13 \text { ] }} \\ 2 & 0.09 & {[0.002-0.37 \text { ] }} \\ 3 & 1.04 & {[0.44-2.45]} \\ 4 & 1.40 & {[0.5-3.89]} \\ 5 & 2.48 & {[0.96-6.42]} \\ 6 & 2.52 & {[0.75-8.46]} \\ 7 & 5.99 & {[1.98-18.1]} \\ \geq 8 & 32.1 & {[18.6-55.8]}\end{array}$

with a score $\leq 3$ (low risk) the mortality rate was $0.1 \%$ at $2 \mathrm{~d}$ and $0.2 \%$ between $2-10 \mathrm{~d}$ and early discharge between $48-72 \mathrm{~h}$ could be applied in slightly more than $60 \%$ of patients (Fig. 1). Recently, we demonstrated that the predictive accuracy of the ZRS was improved by adding baseline NT-proBNP [12]. In this report we studied the value of NT-proBNP measurement at different timepoints over and beyond the ZRS.

\section{Methods}

Patients Our study population consists of patients with the diagnosis of STEMI admitted for PPCI, who were included in the Ongoing Tirofiban in Myocardial Infarction Evaluation (On-TIME) 2 trial [13]. The rationale, design and primary results of this multicentre placebo-controlled, randomised clinical trial have been previously described $[13,14]$.

Briefly, enrolment was from June 2006 to November 2007. Eligible patients were aged $21-85$ years with symptoms of acute myocardial infarction of more than $30 \mathrm{~min}$ but less than $24 \mathrm{~h}$ and ST-segment elevation of more than $1 \mathrm{mV}$ in two adjacent electrocardiograph (ECG) leads. Exclusion criteria were severe renal dysfunction (glomerular filtration rate $<30 \mathrm{ml} / \mathrm{min}$ or serum creatinine $>200 \mathrm{mmol} / 1$ $(>2.5 \mathrm{mg} / \mathrm{dl})$ ), therapy-resistant cardiogenic shock (systolic blood pressure $\leq 80 \mathrm{~mm} \mathrm{Hg}$ for $>30 \mathrm{~min}$ ), persistent severe hypertension (systolic blood pressure $>180 \mathrm{~mm} \mathrm{Hg}$ or di- astolic blood pressure $>110 \mathrm{~mm} \mathrm{Hg}$ ), or a contraindication to anticoagulation, or increased risk of bleeding. Also, patients with left bundle branch block, pregnant and/or breastfeeding women, and patients with a life expectancy of less than one year were excluded. Written informed consent for participation in both the On-TIME 2 study and future data analysis was obtained from each patient. All local ethics committees involved approved the study protocol.

\section{Procedures}

\section{Treatment}

All patients were planned to undergo PPCI and were initially treated according to the study protocol, randomly assigned to (prehospital) treatment with tirofiban $(25 \mu \mathrm{g} / \mathrm{kg}$ bolus and $0.15 \mu \mathrm{g} / \mathrm{kg} / \mathrm{min}$ maintenance infusion for $18 \mathrm{~h}$ ) or placebo. PPCI was performed with standard techniques if the coronary anatomy was suitable for angioplasty. All patients were treated with optimal drug therapy. Final discharge and duration at admission was at the discretion of the treating cardiologist, irrespective of NT-proBNP values or ZRS.

\section{Measurements}

NT-proBNP plasma levels were measured in each patient on admission (after sheath insertion), at $18-24 \mathrm{~h}$ and at 72-96 h after PPCI. 
Table 1 Baseline characteristics of the study group

\begin{tabular}{lll}
\hline Variable & Total $(n=845)$ & $\%$ \\
\hline Age (years) mean \pm SD & $62.0 \pm 11.5$ & - \\
Male gender & 642 & $(76.0)$ \\
Current smoking & 409 & $(48.4)$ \\
Diabetes mellitus & 90 & $(10.7)$ \\
Hypertension & 282 & $(33.4)$ \\
Hypercholesterolaemia & 222 & $(26.3)$ \\
Family history & 340 & $(40.2)$ \\
Prior angina & 104 & $(12.4)$ \\
Previous MI & 69 & $(8.2)$ \\
Previous PTCA & 70 & $(8.3)$ \\
Previous CABG & 12 & $(1.4)$ \\
Previous CVA & 15 & $(1.8)$ \\
Systolic BP, mean \pm SD & $130.70 \pm 24.21$ & - \\
Diastolic BP, mean \pm SD & $76.57 \pm 15.03$ & - \\
Killip > I & 41 & $(4.9)$ \\
Haemoglobin (mmol/l), mean \pm SD & $9.49 \pm 7.16$ & - \\
Troponin ( $\mu$ g/l), mean \pm SD & $0.37 \pm 1.24$ & - \\
Zwolle Risk Score, mean \pm SD & $2.34 \pm 2.13$ & - \\
Hospital stay (days) mean \pm SD & $4.89 \pm 5.64$ & - \\
EF < 30\% & 41 & $(6.2)$ \\
EF 30-40\% & 130 & $(19.8)$ \\
EF $>40 \%$ & 486 & $(74.0)$ \\
\hline All vas $\%$ & \\
\hline
\end{tabular}

All values were denoted as mean \pm SD or absolute numbers and their percentages of the total group, where appropriate

$M I$ myocardial infarction, PTCA percutaneous transluminal coronary angioplasty, $C A B G$ coronary artery bypass grafting,

$C V A$ cerebrovascular accident, $B P$ blood pressure, $E F$ ejection fraction

NT-proBNP plasma levels were measured by an electrochemiluminiscence immunoassay 'ECLIA' on an Elecsys 2010 analyser (Roche, Central Haematology Laboratory, University of Heidelberg, Germany). The ZRS was calculated afterwards in each patient.

\section{Endpoints}

Endpoints were chosen by the ability to preclude early and safe discharge. We took two periods of time: at $48 \mathrm{~h}$ (after $2 \mathrm{~d}$ ) and at $96 \mathrm{~h}$ after PPCI (after $3 \mathrm{~d}$ as recommended in present guidelines) $[1,2]$.

The primary endpoint was death from any cause at $30 \mathrm{~d}$ after withdrawal of blood from which the NT-proBNP level was determined. Secondary endpoints were non-fatal major adverse cardiac events (MACE) and major bleeding until $10 \mathrm{~d}$ after admission. MACE was defined as recurrent myocardial infarction, urgent target vessel revascularisation and malignant cardiac arrhythmias occurring later than $24 \mathrm{~h}$ after PPCI, defined as ventricular fibrillation or sustained and non-sustained ventricular tachycardia. Major bleeding was defined as either intracranial bleeding or overt bleeding with a decrease in haemoglobin $\geq 5 \mathrm{~g} / \mathrm{dl}(\geq 3.1 \mathrm{mmol} / \mathrm{l})$ or a decrease in haematocrit $\geq 15 \%$.

\section{Statistical analysis}

Patients were categorised by percentiles of NT-proBNP levels. We assessed the predictive value of the ZRS, serial NTproBNP levels and the absolute change of NT-proBNP levels from baseline to $18-24 \mathrm{~h}$ (delta NT-proBNP) for the primary endpoint.

We computed and plotted receiver operating characteristic (ROC) curves. A total of 74 patients had missing ZRS values and 36 patients did not have baseline NT-proBNP levels. Three patients had missing values of both ZRS and baseline NT-pro BNP. A multiple missing value imputation procedure was applied in which the values of the NTproBNP levels and the values of the elements of the ZRS were imputed in case they were missing.

We generated 10 datasets and the results of all statistical analyses were pooled across the 10 datasets. Multivariate Cox regression analysis was used to estimate the influence of NT-proBNP and ZRS on 30-day mortality. We adjusted for randomisation, gender, age, renal function (estimated glomerular filtration rate in $\mathrm{ml} / \mathrm{min}$ ), and body mass index in a backward Cox regression with a $p$-value of 0.05 for entry or exit of the variables in the model.

We computed the net reclassification index (NRI) and the integrated discrimination improvement (IDI) to evaluate models with an extra predictor relative to a model with the ZRS alone [15]. The IDI combines the increase in mortality probability for those experiencing an event plus the decrease in mortality probability for those not experiencing an event. The NRI quantifies the net proportion of subjects being correctly reclassified to low or high mortality probabilities when adding a predictor to the model using a cutoff point of $30 \%$.

To analyse models using a linear combination of ZRS and NT-proBNP, we calculated weighted scores for each as follows: $(\beta 1 * \mathrm{ZRS})+(\beta 2 * \ln \mathrm{NT}-$ proBNP$)$, where $\beta 1$ and $\beta 2$ denote $\beta$-coefficients for the ZRS and log NT-proBNP obtained from the multivariate Cox regression model. We used ROC curves to define optimal cut-off values in estimating mortality outcomes. We calculated the pooled areas under the curve (AUC) and 95\% confidence intervals by averaging over the 10 AUCs from the imputed datasets using Rubin's rule [16]. The cut-off values and scores for defining possible early discharge were obtained from the mean scores across the 10 datasets, which gave the highest specificity in combination with a $100 \%$ sensitivity for the primary endpoint (e.g. zero mortality $30 \mathrm{~d}$ after PPCI). A two-sided $p$-value of $\leq 0.05$ was considered to be statis- 
Table 2 Univariate and multivariate Cox proportional hazards analyses for 30-day mortality

\begin{tabular}{|c|c|c|c|c|c|c|}
\hline \multirow[b]{2}{*}{ Variables } & \multicolumn{2}{|c|}{$\begin{array}{l}\text { NT-proBNP baseline } \\
(n=845)\end{array}$} & \multicolumn{2}{|c|}{$\begin{array}{l}\text { NT-proBNP } 18-24 \mathrm{~h} \\
(n=786)\end{array}$} & \multicolumn{2}{|c|}{$\begin{array}{l}\text { NT-proBNP 72-96h } \\
(n=768)\end{array}$} \\
\hline & $P$-value & HR $(95 \% \mathrm{CI})$ & $P$-value & $\mathrm{HR}(95 \% \mathrm{CI})$ & $P$-value & $\mathrm{HR}(95 \% \mathrm{CI})$ \\
\hline \multicolumn{7}{|l|}{$\overline{\text { Univariate analysis }}$} \\
\hline Randomisation placebo vs. tirofiban & 0.011 & $\begin{array}{l}4.10 \\
(1.38-12.19)\end{array}$ & 0.055 & $\begin{array}{l}4.47 \\
(0.97-20.71)\end{array}$ & \multicolumn{2}{|c|}{ Cannot be estimated ${ }^{\mathrm{a}}$} \\
\hline Gender (female vs. male) & 0.132 & $\begin{array}{l}1.97 \\
(0.82-4.75)\end{array}$ & 0.114 & $2.60(0.79-8.52)$ & 0.855 & $\begin{array}{l}0.81 \\
(0.09-7.29)\end{array}$ \\
\hline Age (per year) & $<0.001$ & $\begin{array}{l}1.12 \\
(1.06-1.17)\end{array}$ & 0.006 & $1.09(1.03-1.16)$ & 0.179 & $\begin{array}{l}1.06 \\
(0.97-1.15)\end{array}$ \\
\hline Renal function (eGFR) (per ml/min) & $<0.001$ & $\begin{array}{l}0.95 \\
(0.93-0.97)\end{array}$ & 0.018 & $0.97(0.94-0.99)$ & 0.474 & $\begin{array}{l}0.99 \\
(0.96-1.02)\end{array}$ \\
\hline BMI (per point) & 0.602 & $\begin{array}{l}1.04 \\
(0.91-1.18)\end{array}$ & 0.318 & $1.08(0.93-1.27)$ & 0.964 & $\begin{array}{l}0.99 \\
(0.76-1.30)\end{array}$ \\
\hline Zwolle Risk Score (per point) & $<0.001$ & $\begin{array}{l}1.53 \\
(1.40-1.67)\end{array}$ & $<0.001$ & $1.59(1.38-1.84)$ & $<0.001$ & $\begin{array}{l}1.54 \\
(1.24-1.92)\end{array}$ \\
\hline Zwolle Risk Score $>3$ & $<0.001$ & $\begin{array}{l}9.42 \\
(3.49-25.39)\end{array}$ & 0.008 & $\begin{array}{l}4.94 \\
(1.51-16.20)\end{array}$ & 0.246 & $\begin{array}{l}2.88 \\
(0.48-17.26)\end{array}$ \\
\hline Log NT-proBNP (per point) & $<0.001$ & $\begin{array}{l}2.61 \\
(2.00-3.40)\end{array}$ & $<0.001$ & $\begin{array}{l}9.15 \\
(4.14-20.20)\end{array}$ & 0.001 & $\begin{array}{l}4.45 \\
(1.80-10.99)\end{array}$ \\
\hline Delta NT-proBNP (per 100) & - & - & $<0.001$ & $1.02(1.01-1.04)$ & 0.121 & $\begin{array}{l}0.98 \\
(0.96-1.00)\end{array}$ \\
\hline \multicolumn{7}{|l|}{ Multivariate analysis } \\
\hline Log NT-proBNP (per point) & $<0.001$ & $\begin{array}{l}2.09 \\
(1.59-2.74)\end{array}$ & $<0.001$ & $\begin{array}{l}6.83 \\
(2.94-15.84)\end{array}$ & 0.019 & $\begin{array}{l}3.32 \\
(1.22-9.06)\end{array}$ \\
\hline Zwolle Risk Score (per point) & $<0.001$ & $\begin{array}{l}1.41 \\
(1.27-1.56)\end{array}$ & $<0.001$ & $1.34(1.13-1.57)$ & 0.029 & $\begin{array}{l}1.35 \\
(1.03-1.77)\end{array}$ \\
\hline
\end{tabular}

aall 5 deaths were in patients randomised to placebo

$H R$ hazard ratio, $e G F R$ estimated glomerular filtration rate, $B M I$ body mass index

tically significant. The analyses were performed in SPSS version 22 and SAS version 9.3.

\section{Results}

A total of 861 patients underwent PPCI. Complete followup was present in 845 patients. Baseline characteristics are shown in Table 1. The mean age was 62 years and $76 \%$ were male. Most patients had low Killip class with a post PPCI ejection fraction $>40 \%$. Mean hospital stay was $4.89 \mathrm{~d}$.

Baseline NT-proBNP values ranged from 9-33,927 pg/ml (mean $599 \pm 1883 \mathrm{pg} / \mathrm{ml}$ ) with a median of $138 \mathrm{pg} / \mathrm{ml}$. At $18-24 \mathrm{~h}$ and $72-96 \mathrm{~h}$, NT-proBNP was determined in 786 and 768 patients respectively, and ranged from $45-20,653 \mathrm{pg} / \mathrm{ml}$ (mean $2089 \pm 2738 \mathrm{pg} / \mathrm{ml}$, median $1283 \mathrm{pg} / \mathrm{ml}$ ) and 17-24,119 pg/ml (mean $1618 \pm 2556 \mathrm{pg} / \mathrm{ml}$, median $860 \mathrm{pg} / \mathrm{ml}$ ) respectively.

The primary endpoint was reached in 21 patients. In univariate and multivariate analysis, ZRS and NT-proBNP measured at the different timepoints, but not delta NTproBNP, were strongly associated with 30-day mortality (Table 2).

\section{Predictive value of $\mathrm{ZRS}$ and the NT-proBNP measurements on 30-day mortality}

The AUCs for ZRS and NT-proBNP at the different timepoints ranged from $0.74-0.87$ and $0.87-0.94$ respectively. The AUC for delta NT-proBNP was relatively low: 0.74 (95\% CI 0.48-0.99). Adding NT-proBNP to the ZRS enlarged the AUCs at all timepoints with the largest area at 18-24 h. In addition, also the highest NRI was acquired by NT-proBNP at 18-24h. The integrated discrimination improved significantly after addition of NT-proBNP (Table 3).

\section{Cut-off values and potential early discharge}

Optimal cut-off values were defined (sensitivity 100\%). For NT-proBNP at $18-24 \mathrm{~h}$ and at $72-96 \mathrm{~h}$, these were $<2500 \mathrm{pg} / \mathrm{ml}$ and $<1050 \mathrm{pg} / \mathrm{ml}$ respectively. Interestingly, the cut-off value of the ZRS had to be $<2$. Based on the serial test combination, we created decision rules implying that low-risk patients, eligible for early discharge at $48 \mathrm{~h}$ after PPCI, had to meet a ZRS $<2$ or NT-proBNP $<2500 \mathrm{pg} / \mathrm{ml}$, withdrawn at 18-24 h after PPCI (group 1). Patients eligible for discharge at $96 \mathrm{~h}$ after PPCI had to 
Table 3 Prognostic accuracy of Zwolle Risk Score and NT-proBNP in predicting 30-day mortality at the different timepoints

\begin{tabular}{|c|c|c|c|c|c|c|c|}
\hline- & - & AUC & $95 \% \mathrm{CI}$ & NRI (\%) & $p$ value & IDI (\%) & $p$ value \\
\hline \multirow[t]{3}{*}{ Baseline } & ZRS & 0.87 & $0.79-0.95$ & - & - & - & - \\
\hline & NT-proBNP & 0.91 & $0.86-0.96$ & - & - & - & - \\
\hline & $\begin{array}{l}\text { ZRS + } \\
\text { NT-proBNP }\end{array}$ & 0.94 & $0.90-0.99$ & 9.82 & $<0.0001$ & 11.39 & $<0.0001$ \\
\hline \multirow[t]{3}{*}{$18-24 \mathrm{~h}$} & ZRS & 0.82 & $0.70-0.94$ & - & - & - & - \\
\hline & NT-proBNP & 0.94 & $0.90-0.99$ & - & - & - & - \\
\hline & $\begin{array}{l}\text { ZRS + } \\
\text { NT-proBNP }\end{array}$ & 0.94 & $0.88-0.99$ & 29.28 & $<0.0001$ & 17.10 & $<0.0001$ \\
\hline \multirow[t]{3}{*}{$72-96 \mathrm{~h}$} & ZRS & 0.74 & $0.54-0.94$ & - & - & - & - \\
\hline & NT-proBNP & 0.87 & $0.72-1.00$ & - & - & - & - \\
\hline & $\begin{array}{l}\text { ZRS + } \\
\text { NT-proBNP }\end{array}$ & 0.87 & $0.71-1.00$ & 21.93 & 0.0046 & 7.46 & $<0.0001$ \\
\hline
\end{tabular}

$A U C$ area under the curve, $N R I$ net reclassification index, $I D I$ integrated discrimination improvement

meet a ZRS $<2$ or NT-proBNP $<1050 \mathrm{pg} / \mathrm{ml}$, withdrawn at 72-96 h after PPCI (group 2).

In group 1, 639 patients met the low-risk criteria and 147 patients were at higher risk $(75.6 \%$ and $17.3 \%$ of the total study population, respectively).

Up to $48 \mathrm{~h}$, MACE occurred significantly more often in higher risk patients than in low-risk patients ( 7 vs. 2 patients, $p<0.001)$. Major bleeding occurred in 1 patient in both groups $(0.2 \%$ vs. $0.7 \%, p=0.34)$. As a consequence, 637 patients would have been eligible for discharge at $48 \mathrm{~h}$ after PPCI. This accounts for $75 \%$ of the total study population. Between $48 \mathrm{~h}$ and $10 \mathrm{~d}$ after PPCI, 10 of these patients $(1.2 \%)$ experienced adverse events. MACE occurred in 7 patients $(0.8 \%)$ and major bleeding occurred in 4 patients $(0.5 \%)$. In 1 patient both events occurred. Therefore, 10 readmissions $(1.2 \%)$ within $10 \mathrm{~d}$ after PPCI would have been expected (Fig. 2).

In group 2, 500 low-risk patients $(59 \%)$ could be identified versus 268 patients $(32 \%)$ at higher risk, based on the aforementioned criteria. MACE within $10 \mathrm{~d}$ occurred significantly more often in the higher risk group than in the lower risk group (11/268 (4\%) vs. 4/500 (0.8\%), $p=$ $0.003)$. Major bleeding occurred in 1 patient in the lowrisk group $(0.1 \%)$ and in 5 patients in the higher risk group $(0.6 \%)$. Hence, readmission would have been necessary in 5 patients. The outcome of all screened patients is presented in Supplementary Fig. 1. The different cut points and outcome are presented in Supplementary Table 1.

\section{Discussion}

Our study demonstrates that NT-proBNP, withdrawn at different timepoints after PPCI, improves prognostication of the established ZRS and consequently may improve the scheduling of early hospital discharge.
Although the clinical outcomes in STEMI patients treated by PPCI have been considerably improved, optimising hospital length of stay in these patients is still challenging.

Recent reports make clear that large groups of patients can be discharged safely at or within $48 \mathrm{~h}[6,9,10]$, while the present guidelines recommend discharge after a minimum of $3 \mathrm{~d}[1,2]$. In addition, a lot of international variation in hospital admission duration among low-risk PPCI patients still exists [3, 17-19]. Assuming that the number of low-risk PPCI patients worldwide will increase because of improvement of treatment, there is simultaneously a need for reduction of health care costs. This highlights the necessity for easy tools for risk stratification, in which ideally large proportions of patients could be discharged early. For this purpose, De Luca et al. developed the ZRS. Important variables in this risk model are the success of coronary reperfusion and the occurrence of heart failure. These and other early adverse post PPCI events can also be predicted by NT-proBNP [20-22].

Within this context, NT-proBNP can be considered to be an overlapping variable. The incremental value of adding NT-proBNP to established risk factors may be explained by the fact that biomarker measurement provides more accurate information, without observer variability.

The prognostic significance of the serial changes of plasma NT-proBNP in STEMI patients has previously been studied [23-25]. It was shown that NT-proBNP increases markedly within $24 \mathrm{~h}$. At this timepoint a maximum value is reached after successful reperfusion and then usually decreases, while unsuccessful reperfusion is associated with increased NT-proBNP values at 48-96h $[23,25]$.

Consequently, the change in NT-proBNP concentration could also be predictive. In one report, the difference between NT-proBNP at $72 \mathrm{~h}$ and baseline NT-proBNP was superior to baseline NT-proBNP, but similar to NT-proBNP 
Fig. 2 Feasibility of early discharge (after $2 \mathrm{~d}$ ) in 845 PPCI patients based on ZRS $<2$ or NT-proBNP $<2500 \mathrm{pg} / \mathrm{ml}$ at 18-24 h

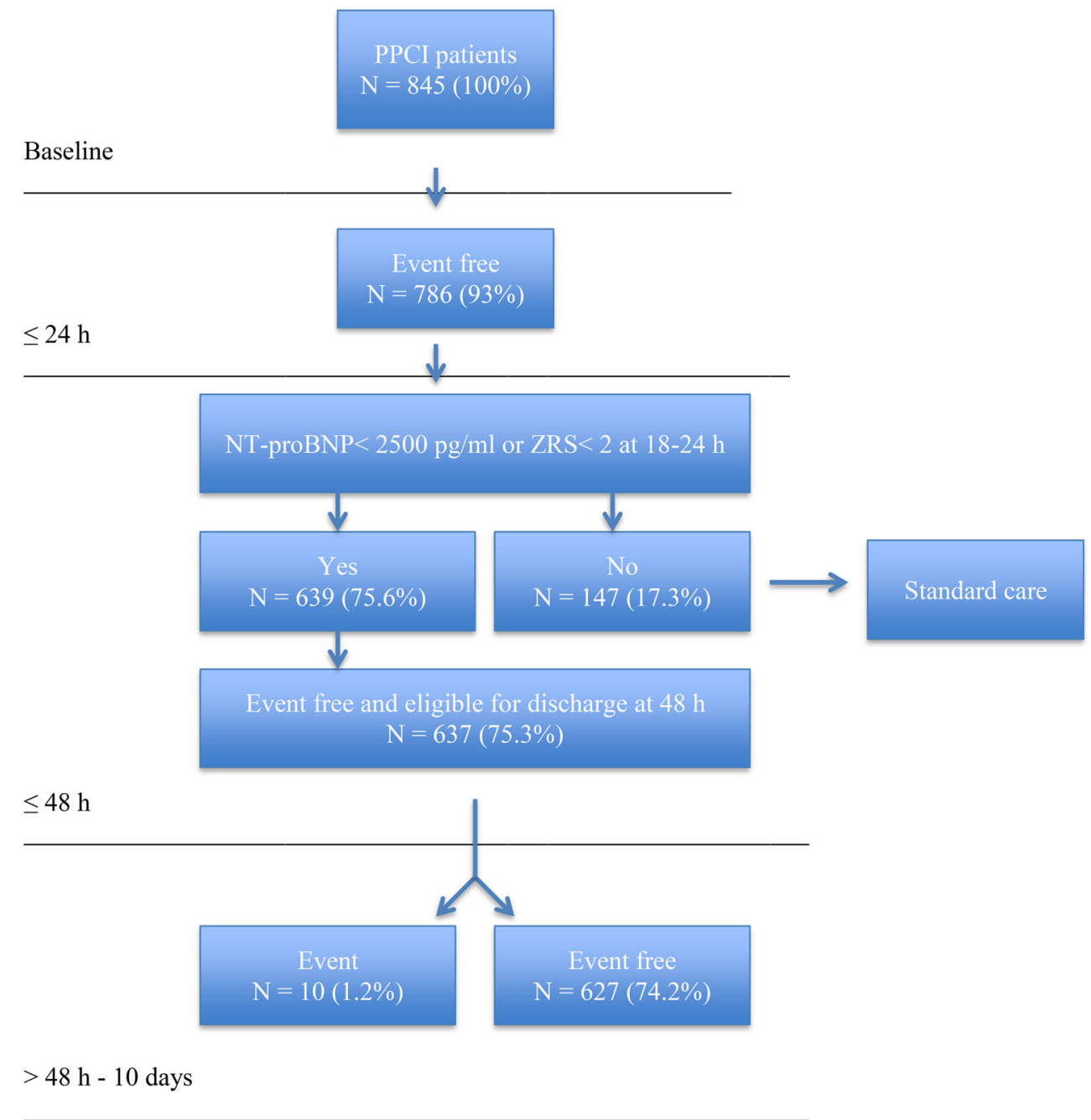

at $72 \mathrm{~h}$ in predicting short-term adverse cardiac events [25]. Interestingly, in our study the change in NT-proBNP was less predictive and cut-off values were difficult to define, since some patients had negative changes in NT-proBNP (or higher values at baseline). However, measurement at two different timepoints is more laborious and would not be useful within the context of early discharge.

Based on our decision rule at $48 \mathrm{~h}$ after PPCI (ZRS $<2$ or NT-proBNP $<2500 \mathrm{pg} / \mathrm{ml}$ at $18-24 \mathrm{~h}$ ), a proportion as large as $75 \%$ of patients could be discharged early. Therefore NT-proBNP measurement at $18-24 \mathrm{~h}$ post PPCI may optimise length of hospital stay in low-risk patients. Furthermore, this risk strategy can also be applied to patients in non-intervention hospitals, since many patients are repatriated in the first $24 \mathrm{~h}$. Especially this group tends to be kept in hospital for a longer period of time [26].

\section{Limitations}

Several limitations of our study have to be noted. Our study lacks a validation cohort to validate the serial model of ZRS and NT-proBNP. Therefore, a future randomised comparison of discharge policies should take place. Although NTproBNP was measured by protocol in every patient, the ZRS was calculated afterwards, so this may be considered retrospective. Although NT-proBNP has also been related to more cardiovascular risk factors than those used in the regression analysis, more potential confounders could not be included because of the number of events. Finally, the patient population was highly selective since all participants took part in a randomised trial with aforementioned exclusion criteria.

\section{Conclusion}

NT-proBNP at different timepoints improves prognostication of the ZRS. Particularly at $18-24 \mathrm{~h}$ post PPCI, the 
largest group of patients that potentially could be discharged early was identified.

Acknowledgements We thank Mrs. Vera Derks and Dr. Petra Koopmans for their contributions to the article.

Conflict of interest D.A.A.M. Schellings, A.W.J. van't Hof, J.M. ten Berg, A. Elvan, E. Giannitsis, C. Hamm, H. Suryapranata and A. Adiyaman declare that they have no competing interests.

Open Access This article is distributed under the terms of the Creative Commons Attribution 4.0 International License (http:// creativecommons.org/licenses/by/4.0/), which permits unrestricted use, distribution, and reproduction in any medium, provided you give appropriate credit to the original author(s) and the source, provide a link to the Creative Commons license, and indicate if changes were made.

\section{References}

1. Steg PG, James SK, Atar D, et al. The Task Force on the management of ST-segment elevation myocardial infarction of the European Society of Cardiology (ESC). ESC guidelines for the management of acute myocardial infarction in patients presenting with STsegment elevation. Eur Heart J. 2012;33:2569-619, www.escardio. org/guidelines.

2. O'Gara PT, Kushner FG, Ascheim DD, et al. American College of Cardiology Foundation/American Heart Association Task Force on Practice Guidelines. 2013 ACCF/AHA Guideline for the management of ST-elevation myocardial infarction: a report of the American College of Cardiology Foundation/ American Heart Association Task Force on Practice Guidelines. Circulation. 2013;127:e362-e425.

3. Chin CT, Weintraub WS, Dai D, et al. Trends and predictors of length of stay after primary percutaneous coronary intervention: a report from the CathPCI registry. Am Heart J. 2011;162:1052-61.

4. Grines CL, Marsalese DL, Brodie B, et al. Safety and cost-effectiveness of early discharge after primary angioplasty in low risk patients with acute myocardial infarction. PAMI-II investigators. Primary angioplasty in myocardial infarction. J Am Coll Cardiol. 1998;5:967-72.

5. Branca G, Capodanno D, Capranzano P, et al. Early discharge in acute myocardial infarction after clinical and angiographic risk assessment. J Cardiovasc Med (Hagerstown). 2008;9:858-61.

6. Jirmar R, Widimsky P, Capek J, Hlinomaz O, Groch L. Next day discharge after successful primary angioplasty for acute ST elevation myocardial infarction. An open randomized study 'Prague-5'. Int Heart J. 2008;49:653-9.

7. Kotowycz MA, Cosman TL, Tartaglia C, et al. Safety and feasibility of early hospital discharge in ST-segment elevation myocardial infarction - a prospective and randomized trial in low risk primary percutaneous coronary intervention patients (The Safe-Depart Trial). Am Heart J. 2010;159:117.e1-117.e6.

8. Laarman GJ, Dirksen MT. Early discharge after primary percutaneous coronary intervention. Heart. 2010;96:584-7.

9. Jones DA, Rathod KS, Howard JP, et al. Safety and feasibility of hospital discharge 2 days following primary percutaneous intervention for ST-segment elevation myocardial infarction. Heart. 2012;98:1722-7.

10. Noman A, Zaman AG, Schechter C, Balasubramaniam K, Das R. Early discharge after primary percutaneous coronary intervention for ST-elevation myocardial infarction. Eur Heart J Acute Cardiovasc Care. 2013;2:262-9.

11. De Luca G, Suryapranata H, van't Hof AWJ, et al. Prognostic assessment of patients with acute myocardial infarction treated with primary angioplasty: implications for early discharge. Circulation. 2004;109:2737-43.

12. Schellings DAAM, Adiyaman A, Giannitsis E, et al. Early discharge after primary percutaneous coronary intervention: the added value of NT-proBNP to the Zwolle Risk Score. J Am Heart Assoc. 2014;3(6): 0001089.

13. Van't Hof AWJ, ten Berg JM, Heestermans T, et al. Ongoing tirofiban in myocardial infarction evaluation (On-Time) 2 study group. Prehospital initiation of tirofiban in patients with ST-elevation myocardial infarction undergoing primary angioplasty (OnTIME 2): a multicentre, double blind, randomised controlled trial. Lancet. 2008;372:537-46.

14. On behalf of the On-TIME 2 investigators, Van't Hof AWJ, Hamm $\mathrm{C}$, Rasoul $\mathrm{S}$, et al. Ongoing tirofiban in myocardial infarction evaluation (On-TIME) 2 trial: rationale and study design. EuroIntervention. 2007;3:371-80.

15. Pencina MJ, D’Agostino RB Sr, D’Agostino RB Jr.. Evaluating the added predictive ability of a new marker: From area under the ROC curve to reclassification and beyond. Stat Med. 2008;27:157-72.

16. Rubin DB. Multiple imputation for nonresponse in surveys. New York: J. Wiley \& Sons; 1987.

17. Kaul P, Newby LK, Fu Y, et al. International differences in evolution of early discharge after acute myocardial infarction. Lancet. 2004;363:511-7.

18. AMI-Florence Working Group, Barchielli A, Balzi D, Marchionni $\mathrm{N}$, et al. Early discharge after acute myocardial infarction in the current clinical practice. Community data from the AMI-Florence Registry, Italy. Int J Cardiol. 2007;114:57-63.

19. Claeys MJ, Sinnaeve PR, Convens C, et al. Inter-hospital variation in length of hospital stay after ST-elevation myocardial infarction: results from the Belgian STEMI registry. Acta Cardiol. 2013;68:235-9.

20. Jarai R, Huber K, Bogaerts K, et al. ASSENT-IV-PCI investigators. Plasma N-terminal fragment of the prohormone B-type natriuretic peptide concentrations in relation to time to treatment and thrombolysis in myocardial infarction (TIMI) flow: a substudy of the assessment of the safety and efficacy of a new treatment strategy with percutaneous coronary intervention (ASSENT IV-PCI) trial. Am Heart J. 2010;159:131-40.

21. Blom JR, van't Hof AWJ, Henriques JPS, et al. NT-proBNP: a marker for successful myocardial reperfusion in AMI patients treated with primary percutaneous coronary intervention. Eur J Heart Fail. 2004;6:749-52.

22. Korea Acute Myocardial Infarction Registry Investigators, Kwon TG, Bae JH, Jeong MH, et al. N-terminal pro-B-type natriuretic peptide is associated with adverse short-term clinical outcomes in patients with acute ST-elevation myocardial infarction who underwent primary percutaneous coronary intervention. Int $\mathrm{J}$ Cardiol. 2009;133:173-8.

23. Buchner S, Debl K, Barlage S, et al. Dynamic changes in N-terminal pro-brain natriuretic peptide in acute coronary syndromes treated with percutaneous coronary intervention: a marker of ischemic burden, reperfusion and outcome. Clin Chem Lab Med. 2010;48:875-81.

24. Ezekowitz JA, Théroux P, Chang W, et al. N-terminal pro-brain natriuretic peptide and the timing, extent and mortality in ST elevation myocardial infarction. Can J Cardiol. 2006;22:393-7.

25. Ezekowitz JA, Théroux P, Welsh R, et al. Insights into the change in brain natriuretic peptide after ST-elevation myocardial infarction (STEMI): Why should it be better than baseline? Can J Physiol Pharmacol. 2007;85:173-8.

26. Kotowycz MA, Syal RP, Afzal R, Natarajan MK. Can we improve length of hospitalization in ST elevation myocardial infarction patients treated with primary percutaneous coronary intervention? Can J Cardiol. 2009;25:585-8. 